INTERNATIONAL STABILIZATION POLICY UNDER FLEXIBLE EXCHANGE RATES

H. Robert Heller

Being the only speaker at this conference to represent the business sector, I will focus my remarks on the effects of the flexible exchange rate system -- as it has operated throughout the seventies -- on the business sector. In particular, I will discuss three aspects of the topic: First of all, I will address myself to the question of whether the flexible exchange rate system and its actual operation in the years since 1971 have served the economy, and in particular, the business sector well. Second, I will offer my views as to what policy changes would improve the operation of the present system. Third, I will adopt a longer perspective and indicate what international monetary reforms might improve the operation of the system.

THE CONSEQUENCES OF FLEXIBLE EXCHANGE RATES

The operation of the flexible exchange rate system since 1971 has entailed a significant increase in costs to the business sector. In particular, there are adverse effects on international trade, international capital movements, and foreign investment. I will also argue that the increased costs to the private sector were not offset by a greater freedom for the policymakers to pursue more appropriate macroeconomic stabilization policies or other direct savings realized by the public sector.

Dr. Heller is Vice President for International Economics, Bank of America, NT + SA, San Francisco, California. 
But I should like to make it clear at the outset that there are at present no viable alternatives to the flexible exchange rate system. As long as there are large differences in inflation rates among natjons, a fixed exchange rate system will not be viable. What we perceive as the cost of flexible exchange rates is therefore truly the cost associated with high and differential inflation rates. Nevertheless, the flexible exchange rate system does little to make countries adopt noninflationary policies. It is in that sense that the flexible exchange rate system has also been associated with fluctuating exchange rates and the costs thereof.

\section{Internationa Trade}

The thesis has been advanced that flexible exchange rates discourage foreign trade. There are several reasons for expecting a dampening effect on foreign trade under a system of flexible exchange rates. First of all, there is simply the increased uncertainty of exchange rate fluctuation that will have to be borne by one or the other party to trade transactions. It is important to note that we are not involved in a zero-sum game here. While in simple arithmetic terms one party's gain must be the other party's 10s5, the increased uncertainty will affect both parties to the transaction. As long as people are risk-averse, there will be a net loss because the welfare losses associated with a $50 / 50$ chance of losing one million dollars are greater than the welfare gains of a $50 / 50$ chance of winning one million dollars. That's the reason why we find few corporate presidents wagering last quarter's corporate earnings on a double or nothing bet on the outcome of this weekend's football game or at the roulette wheels in Las Vegas. 
Second, while it is possible to engage in forward currency transactions to eliminate the foreign exchange risk, one should keep in mind that there is not only a brokerage cost associated with these transactions, but that there exist no organized forward markets for the vast majority of currencies -- especially those of the developing countries. The system therefore has an inherent bias against trade with the developing countries -- some of which have the widest exchange rate fluctuations due to their high inflation rates.

Third, there is the natural competitive instinct that makes the businessman think -- "maybe I should wait one more week before I cover in the forward market to obtain a better rate. Or worse yet, if I cover this week, and my competitor obtains a better forward rate next week, then I will lose the contract altogether." If the rate turns in a disadvantageous direction, the businessman may then not even bid on the contract.

Fourth, there are costs for the individual firm associated with the necessity to collect information on exchange rates, to ensure that proper accounting and legal procedures are followed, to maintain staff to call up the banks, make appropriate calculations, keep records, and perhaps even hire an economist or consulting firm to prepare a foreign exchange forecast.

A11 these costs are deadweight losses to the private sector as a whole, because we are playing a zero sum game where one firm's foreign exchange gains will be another firm's foreign exchange losses. Gone are the good old days when one merely had to outwit the central bank that could not make up its mind as to how much longer it should attempt to maintain an exchange rate that had long ago becone unrealistic. 
Instead, the private sector has to maintain all the required ancillary services just in an attempt to stay even and not to wind up on the losing side of the currency seesaw.

United States businessmen are particularly affected by the introduction of flexible exchange rate because most international trade used to be denominated in U.S. dollars. Now, only half of world trade is denominated in dollars and half in other currencies.

In particular, firms entering new markets often find that they have to adapt to local conditions if they wish to penetrate new markets. National pride of some of the newly developing countries may also play an important role in their insistence to utilize their own currency to an increasing extent.

While some empirical studies failed to find an effect of flexible exchange rate on the volume of international trade, I find this evidence hard to believe.

The simplest of all possible calculations show that foreign trade increased at an annual rate of 8.8 percent in real terms during 196373, while the rate of increase in $1973-75$ amounted to only 4.3 percent per annum. That is, the rate of increase in the volume of international trade was cut in half under the flexible exchange rate system. While it is true that this does not imply that the flexible exchange rate system caused this decline,-- and $I$ will have to say more on that topic later - - it is certainly true that the flexible exchange rate system did not prevent the decline in the trade volume either.

Finally, I need not point out that the myth that flexible exchange rate would always balance our international trade is nothing but that -- a myth. People who drew the opposite conclusion from textbooks in 
international economics forgot to read the fine print: namely that it was assumed that there were no international capital movements. Only in such a world can perfect purchasing power parity hold and will imports automatically be balanced by exports of equal value.

In the real world, capital movements are very much with us, and they are not so much determined by actual international price differentials, but by the expectation of price level changes at some future date.

\section{Capital Movements}

This brings me to the second major point to be covered: the impact of flexible exchange rate on international capital movements.

First of a11, it is clear by now that international capital movements have not served as the great stabilizer of exchange rates that they are supposed to be. According to theory, well-informed private speculators will act to stabilize the exchange rate, buying the currency when it is low and selling it when it is high. But who are these wellinformed speculators? The actors with the greatest amount of expertise in the area, the large commercial banks, are highly reluctant to take open foreign exchange positions. They are trade-oriented, not speculation-oriented. Much more money is to be made by actively trading in the market, and earning a sma 11 spread on each transaction than by maintaining an open position and hoping for the best. The situation is not unlike the one of a grocery store owner, who makes his morey buying and selling tomatoes, and not by hoping to make a killing in the market when the tomato crop in Mexico goes sour and the price skyrockets. U.S. Treasury data show that on average U.S. commercial banks were 
holding less than $\$ 100$ million in open foreign exchange positions. This aggregate amount for ał 1 U.S. banks is not much larger than some of the individual transactions foreign exchange traders are called upon to execute.

This leaves private corporations and individuals as the potential market stabilizers. While corporations do take foreign exchange positions, they are typically designed to offset some commercial transactions rather than as a deliberate attempt to take an open position. The corporate treasurer who attempts to make a career out of realizing foreign exchange profits is a rare, and probably short-lived, breed. Instead, the typjcal corporate strategy can more properly be described as one of foreign exchange loss-avoidance rather than of foreign exchange speculation.

The final group -- private individuals -- is certainly increasingly active in the market. They are probably more active in the organized non-bank foreign exchange markets, such as the IMM (International Monetary Market, a division of the Chicago Mercantile Exchange) than in the comnercial bank market. Prior to the Herstatt calamity, private speculators had access to the bank market largely through small banks. Since 1974 most major banks have reduced the foreign exchange 1 ines made avajlable to the smaller banks, thereby sharply limiting their access to the interbank market. Consequently, most individuals are active in the IMM and the New York exchanges. As a rough generalization, it may be said that these exchanges are equal to the transactions carried out by one major U.S. bank as far as its influence on the market is concerned. 
Considering all this, it still remains true that a speculator is able to make profits more consistently by running with the markets rather than by taking a position and hoping for a turn-around in the market. To try to pinpoint market turn-arounds is exceedingly difficult as everyone who has tried his luck at it knows.

The upshot is that the herd instinct in foreign exchange narkets is still very powerful and the well-informed speculating loner is the exception rather than the rule. Consequently, speculative activity may well accentuate rather than reduce exchange rate fluctuations.

\section{Investment}

The uncertainty surrounding the exchange value of the currencies has also taken its toll on the willingness of investors to engage in foreign direct investments and in long-term construction activity abroad.

Increasingly, foreign countries insist on denominating long-term construction contracts in their own currency, forcing the Americar businessman to shoulder the foreign exchange risk. Foreign direct investment and long-term construction projects that may take five or even ten years to complete are particulariy affected by the exchange rate uncertainty because there are no organized forward markets in which such long-term exposures may be hedged. In addition, many of these projects are located in countries for whose currencies not even regular forward markets or capital markets exist, thereby making hedging an immpossibility. Under such circumstances the onty options open to the businessman are to assume the foreign exchange risk or to forget about the contract. 
Foreign investment activicy is also greatly complicated by changing currency values. What might be a profitable foreign operation at one exchange rate may rapidly become unprofitable as the foreign exchange rate changes. In addition, arbitrary accounting rules -- such as FASB 8 -- may have significant impact on a firm's profit and loss position regardless of the profitability of the underlying manufacturing activities. At best, the effects of exchange rate changes on the balance sheet make it much more difficult to evaluate the profitability of the investment. At worst, it leads to erroneous investment decisions and ultimately a retreat from international activities.

\section{The Public sector}

The question arises whether the additional costs imposed upon the private sector of the economy are counterbalanced by benefits to the public sector of the economy. While this is a difficult question to answer, I believe that it must be answered in the negative.

Benefits may accrue to the economy by the creation of an economic environment that would bring about a greater freedom to pursue appropriate economic policies, foster higher growth, or lessen inflationary pressures. On al1 these counts the actual experience with fiexible exchange rates has been discouraging. Of course, the ultimate proof of any of these propositions is impossible to attain. It would require a replay of history under a fixed exchange rate regime -- and that is clearly impossible.

Economic inference makes it also difficult to see why a floating exchange rate regime should be characterized by high growth and little inflation. The fundamental point is that the flexible exchange rate 
iystem does not lessen the balance of payments constraint -- it merely zhanges its nature.

It is difficult to decide whether a loss of foreign exchange reserves or a fall in the foreign exchange rate provides a more rigid policy constraint. But while the loss of foreign exchange reserves under a fixed exchange rate system provides not only a self-limiting constraint in that no country has either unlimited reserves or unlimited access to international credit, the loss of reserves eventually forces the adoption of a more restrictive monetary policy which will tend to bring the country in line with the global inflation rate.

Flexible exchange rates do not have such self-limiting properties, and it has instead been suggested that the depreciation of a currency may well lead to the development of vicious circles where currency depreciation brings about more inflation because of its immediate impact on the price of imported commodities. The rekindled inflationary forces in turn may force a further depreciation and so on.

While the statistical evidence on the validity of this theory is far from complete and doubtful, it stands to reason that a fixed exchange rate system operates as an equalizer of international inflation differentials, while a flexible exchange rate system tends to accentuate inflation differentials.

As far as the international businessman is concerned, it is clear which one constitutes the more attractive environment: given a choice between similar -- even if high -- inflation rates in al1 countries and an environment or widely divergent inflation rates, the businessman is likely to choose the former one. 
However, it is questionable which one of the two alternatives is best for all people of the world.

For the central banker, floating rates do not seem to have brought a more relaxing lifestyle either. Gross foreign exchange market intervention on behalf of central banks amounted to a record of $\$ 72$ bitlion dollars in the half year ending July 31 , 1979. To put this number into proper perspective, let us remind ourselves that the total foreign exchange reserves of al 1 countries in the world totalled the same amount in 1971, the last year of the fixed exchange rate system. Increasing, rather than less, official intervention has been the hal1mark of the flexible exchange rate system in the seventies.

\section{The International Monetary System}

The exchange value of the dollar against the DM (deutsche mark) or SFR (Swiss franc) has been cut in half over the Tast decade. That such a precipitous decline in the value of the world's leading reserve currency cannot be without impact on the role of this currency in the world and on the international monetary system itself goes without saying.

A superficial glance at the percentage of official foreign exchange reserves held in the forn of dollars shows that the market share of the dollar has remained virtually constant at 80 percent. However, these figures are - in my opinion - - highly misleading. While high U.S. Treasury officials have argued that the dollar purchases on behalf of foreign central banks were proof of their confidence in the U.S. dollar, it is probably more appropriate to argue that these official dollar purchases were largely the result of intervention designed to stop an even further slide of the dollar. The foreign central banks 
were the reluctant victims of a declining dollar and not the exuberant investors they are made out to be.

In fact, foreign central banks of floating currency countries have reduced the share of dollars in their foreign exchange reserve portfolio from over 90 percent in 1970 to less than 75 percent in 1976 . So have the central banks of countries other than the main industrialized countries, who acquired the dollars as a result of their intervention policy. In other words, those central bankers that were free to consider the dollar as a portfolio investment instead of an intervention currency did in fact switch away from the dollar.

The decline of the dollar in official foreign exchange portfollos was also masked to some extent by the even faster decline of the British pound in international significance. Central banks have switched out of pounds and purchased DM over the last decade, so that the position of the pound is now held by the mark. It stands to reason that central banks would have wanted to acquire DM anyhow, and had it not been for the fact that the pound was even weaker than the dollar, the switch out of dollars would certainly have been more pronounced.

In addition to the decline in the value of the U.S, dollar, there are other reasons that make it attractive for central banks to diversify their foreign exchange portfolios to an increasing extent. First of a11, it is clear that a diversified currency portfolio increases its overall stability. Second, as exchange rates fluctuate it may be prudent to hold reserves in the currency of one's trading partners. Third, the same argument applies to the denomination of the currency in which the country's external debt is denominated. In that connection it is important to note the very rapid swing away from 
dollar-denominated international bond issues in recent years. In 1976 the value of dollar-denominated international bond issues was still three times as large as the value of OM bonds, but by 1978 the DM volume was equal to the dollar volume. Consequently, the need to make amortization and interest payments in marks will continue to increase in the future and with it the desirability of holding marks as 1 iquid reserve assets.

We may therefore conclude that: one, the flexible exchange rate system has been associated with a significant increase in costs to the private sector; two, that it has not brought about a climate for the conduct of more effective stabilization policies; three, that it has not decreased the cost of intervention for central banks; and four, that it has fostered the decline of the dollar as the world's leading currency.

I will now consider several measures that might improve the effectiveness of stabilization policies under the flexible exchange rate system.

IMPROVING THE OPERATION OF THE FLEXIBLE EXCHANGE RATE SYSTEM

At the present time, there exists no viable alternative to the flexible exchange rate system. The main reason for this conclusion is simple: as long as differential inflation rates among countries prevail, it is not possible to impose or to achieve exchange rate stability. The framers of the new Article IV of the IMF (International Monetary Fund) Articles of Agreement were fully aware of this point: exchange rate stability cannot be achieved without internal stability in the relevant economies. To blame the flexible exchange rate system for 
the additional costs that have to be borne -- especially by the private sector -- would be to blame the messenger for the bad news.

Nevertheless, there are certain improvements in the operation of the flexible exchange rate system that can be made in order to enhance its effectiveness and to reduce the costs associated with it. These are the lessons we can learn from the experience gained during the seventies to enhance the operation of the international monetary system during the eighties.

It will be convenient to group the suggestions into two broad categories: those pertaining to improving U.S. monetary and exchange rate policy and those relevant for the international monetary system.

\section{Possible U.S. Pollicy Improvements}

It should be feasible to improve U.S. monetary and exchange rate policy with a view towards enhancing the stability of exchange rates.

The first set of suggested steps pertains to the conduct of U.S. monetary policy, and it is gratifying that the Federal Reserve has already announced the adoption of monetary targets and their supremacy over interest rate targets. The experience of having to chase the market interest rates higher and higher during the summer of 1979 while rea interest rates remained negative and the money supply grew out of control was an important factor in influencing the 0ctober 1979 decision to use bank reserves instead of the Federal Funds rate as an immediate operating target.

of course, both the Federal Reserve and the other market participants wil have to gain experience and confidence in the operation of the new system to ensure its proper functioning. In that connection it 
is somewhat disconcerting to note that the introduction of the new system was not handled in a fashion designed to make its implementation as smooth as possible, but was conducted in an abrupt and disruptive fashion that resulted in the introduction of uncertainty, confusion over the intentions of the Federal Reserve, and thereby greater market instability -- the very symptoms that the Federal Reserve action should have helped to alleviate rather than to foster.

Nevertheless, the overall thrust of the new policy is good, and once the dust has settled the targeting on the monetary aggregates should prove to be a significantly better system than the interesttarget approach used in the past.

The operation of the system could be further enhanced by the announcement of intemediate range monetary targets as guideposts for the Federal Reserve. Such three to five-year targets could be very helpful in signalling to the private sector the clear intention of the Federal Reserve to reduce monetary growth rates to non-inflationary levels and to provide a framework for orderly and sustained economic growth. of course, such targets must be strictly adhered to, so that confidence in the policy statements of the authorities will be enhanced. To use the announcement of official targets to influence expectations without appropriate follow-through and implementation merely creates a climate in which all policy pronouncements will be doubted and will therefore become less and less effective.

In that connection it is also important to have a realistic monetary growth target supported by a coordinated fiscal strategy. To announce a reduced monetary growth target while the public sector borrowing requirements are expected to increase drastically might not 
constitute a credible policy package in that context. Monetary policy cannot work in isolation and must be seen as one ingredient in a coordinated policy package aimed at achieving economic stability.

The central bank can also play an important role in reducing erratic exchange rate fluctuations as the November 1978 policy actions showed. There is a significant difference between intervention to maintain an exchange rate that has become unrealistic, and intervention to turn around a market trend that has become disequilibrating. Central banks have now learned the lesson that there is little to be gained by trying to maintain an unrealistic exchange rate. Not only are the foreign exchange losses incurred staggering, but the domestic consequences of such i11-advised intervention are also disadvantageous. A central bank that sells its currency in foreign exchange markets to keep it from appreciating increases the monetary base by providing more of its own currency. This in turn increases inflationary pressures at a later date, thereby leading to domestic instability.

Similarly, a central bank that depends on unrealistically high exchange rates will soon find that the foreign exchange reserve losses are staggering and will be forced to permit a more drastic exchange rate realignment at a later date or to impose exchange controls with all undesirable consequences attached to such measures.

In contrast, central bank intervention to turn the foreign exchange market around and to end a trend that has clearly become destabilizing can be highly successful as the November 1978 U.S. policy measures showed. The essential ingredient to the success of such an intervention policy is the simultaneous adoption of domestic monetary policy measures that attack the root cause of the exchange rate 
movement. It wi11 be recalled that from November 1978 until Apri] 1979 there was virtually no monetary growth in the U.S. This was taken by the markets as a signal that the Federal Reserve was prepared to pursue a tight, anti-inflationary monetary policy and the dollar remained stable during that period. In April 1979 the money supply again began to grow at an excessive rate, driving up interest rates, increasing inflationary pressures, and bringing the dollar under renewed pressure, thereby necessitating the November 1979 policy actions.

\section{Possible Improvements in the International Monetary system}

It is my belief that the world economy could function quite well under a dollar standard, where the dollar is the dominant gobal unit of account, transaction currency, and store of value. An indispensable precondition for the functioning of such a system is the unquestioned stability of the dollar in terms of real purchasing power. Domestic inflation and the accompanying erosion of the currency's value in foreign exchange and international commodity markets will have the unavoidable consequences of reducing the dollar's international role. The British inflation and decline in the value of the pound resulted in the elimination of that currency from the reserve currency status that it once enjoyed. Continued double-digit inflation in the United States will undoubtedly bring about the demise of the dollar as a reserve currency as well.

It is up to the United States to get its own house in order if she wishes to preserve the international stature of the dollar. The benefits flowing to the international community as a result of such action would undoubtedly be great. 
The most likely alternative to a dollar standard is at present the development of a multiple-currency reserve standard, where several currencies, in addition to the dollar, will serve an international role. However, it should be realized that such a multiple-currency standard is inherently unstable and is likely to lead ultimately to severe financial and economic disturbances. For the same reason that bimetallism proved to be unstable, it will be found that relatively small differences in national inflation rates among the different key currencies will lead to relatively large shifts in capital flows among these countries. Such capital flows will exacerbate balance of payments difficulties, as capital is likely to flow into a country that a) ready enjoys a current account surplus. Consequently, exchange rate movements will be accentuated, official intervention will have to become even larger, or capital controls will have to be introduced. Uttimately, it is likely that capital controls cannot be avoided, and the very benefits of a liberal international financial order will be destroyed.

The only feasible realistic alternative to a multiple-currency system is at present a system based on the SDR (Special Drawing Rights). The recent decline of the dollar has consequently led to a renewed interest in the SDR as an international reserve asset. This turn of events is not without irony, because the SDR was born in 1968 out of fear that there might be a shortage of dollars when the U.S. balance of payments would return to surplus. Instead, the SDR is now likely to assume a larger role on the international economic scene because there is a perceived surplus of dollars. The renewed interest in 
a dollar/SOR substitution account is the natural outgrowth of these developments

To move the SDR firmly to the center of the international monetary system would require at least three steps: to base the IMF exclusively on the SDR, to make the SDR usable -- that is transferable -among private entities, and to make the SDR inflation-proof. Let me briefly elaborate on each one of these points.

Recently, the Economic Counsellor of the IMF, Mr. J. J. Polak, set forth a plan that would make the SDR the centerpiece of all IMF operations. This innovative and farsighted suggestion would significantly enhance the importance of the SDR and make it a more central asset in the international monetary system. In addition, such a move would also have the advantage of unifying many of the Fund operations that are now proliferated among an ever larger and more complex variety of "accounts" and "facilities."

Second, the SDR should be made transferable among private as wel1 as public holders. When the SDR is freely traded in international financial markets its usefulness and liquidity will be greatly enhanced. The SOR is not likely to assume a significant role in world financial markets until it is also used widely for comercial transactions that create a need to effect payments in SDRs. But if SDRs are not freeTy transferable between private and official holders, it is unlikely that they wi11 assume an important role as an international means of payment. Transferability of the SDR among private parties is therefore essential if the international monetary system is to be based firmly on the SDR. 
Third, the SDR should be turned into a true global standard of value by rendering it inflation-proof. Traditionally, gold has fulfilled the role of an international standard of value but official actions and the recent speculative fever have deprived gold of its status as a stable measuring rod. Instead, it has become a highly speculative commodity.

As presently constituted, the SDR offers some protection against the risk inherent in differential inflation rates by providing the holder with a diversified currency basket. But it should be noted that the value of this currency basket in terms of real purchasing power deteriorates along with the weighted average of the inflation rates experienced by the sixteen countries represented in the SDR basket. A superior inflation hedge is always available to the investor -- be it a monetary authority or a private entity -- by not holding the currencies of high inflation countries. The SDR, as presently constituted, forces the investor to accept the depreciating currencies of the high inflation countries that do not enter the SDR interest rate calculations based on the five most important currencies only. Hence, the SDR as presently constituted is not a particularly attractive asset.

The inflation-proofing of the SDR would make it a truly superior international asset that could play an increasingly important role on the world financial scene by providing a universal unit of account, a monetary transaction medium, and a stable store of value. Such an inflation-proofing of the SDR could be accomplished by linking it to a price index of the sixteen countries making up the SDR basket. Of course, there are many operational problems to be considered, but these 
are not inherently more complex than those that had to be resolved when the SDR as currently constituted was created.

of course, there remains a very disturbing thought: If all the individual countries are unwilling or unable to take the necessary steps to bring inflation under control, why should we assume that all these nations acting in concert through an institution would be any more willing or able to act in a manner that would expose their own shortcomings? Nevertheless, it may be possible to achieve an international consensus on the creation of such an asset because the alternative of continued international monetary disruption is associated with high costs for all.

The oniy other feasible alternative for the eighties is a rapid reduction in the U.S. inflation rate, such that the international role of the dollar will be preserved in the decades to come. Without a stable dollar that can serve as the anchor of the international monetary system there is not likely to be exchange rate stability. The elimination of inflation in the U.S. and in other countries will therefore be a precondition for the improvement of the operation of the international monetary system. Stability cannot be imposed by the international monetary system or found by manipulating the system. International monetary and exchange rate stability can be achieved only by first attaining domestic stability. 